\title{
Effect of a Heated Breathing Tube on Efficacy, Adherence and Side Effects during Continuous Positive Airway Pressure Therapy in Obstructive Sleep Apnea
}

\author{
Wolfgang Galetke ${ }^{a, b}$ Eleonore Nothofer ${ }^{b}$ Christina Priegnitz ${ }^{b, c}$ \\ Norbert Anduleit ${ }^{\mathrm{b}}$ Winfried Randerath ${ }^{\mathrm{b}, \mathrm{c}}$ \\ ${ }^{a}$ Krankenhaus der Augustinerinnen, Cologne, ${ }^{b}$ Institute for Pneumology, Witten/Herdecke University, Witten, and \\ ${ }^{c}$ Krankenhaus Bethanien, Solingen, Germany
}

\section{Key Words}

Continuous positive airway pressure $\cdot$ Obstructive sleep apnea $\cdot$ Humidification $\cdot$ Heated breathing tube .

Adherence $\cdot$ Side effects

\begin{abstract}
Background: Heated breathing tubes were developed to improve heated humidification in continuous positive airway pressure (CPAP) therapy of patients with obstructive sleep apnea syndrome (OSAS). Objectives: We wanted to investigate the influence of a heated breathing tube on patients' satisfaction with the treatment, the rate of side effects and the adherence to treatment. Methods: Eighty-eight patients with primarily diagnosed OSAS were treated in a randomized, controlled, single-blind trial for 12 months either with a CPAP system plus conventional heated humidifier or with a CPAP system plus heated humidifier and an integrated heated breathing tube. Results: Both systems improved the respiratory disturbances and the quality of sleep in a similar manner. The difference in the overall satisfaction with the treatment (subscale 3 of the visual analogue scale) between the two treatment groups was not statistically significant (mean difference $-14.1,95 \% \mathrm{Cl}-28.7$ to $0.6 ; \mathrm{p}=0.059$ ). The rate of side effects and the quality of life did not differ significantly between the two groups. The patients with the
\end{abstract}

heated breathing tube used the treatment on average $1 \mathrm{~h}$ longer, but this was not statistically significant (4.96 \pm 1.95 vs. $3.90 \pm 2.54 \mathrm{~h} /$ night; $\mathrm{p}=0.06$ ). Conclusions: Controlled heated breathing tube humidification as compared to conventional heated humidification improves neither the adherence to treatment, nor the rate of side effects, nor the quality of life in nonselected OSAS patients.

(c) 2016 S. Karger AG, Basel

\section{Introduction}

Continuous positive airway pressure (CPAP) remains the therapy of choice for treating obstructive sleep apnea syndrome (OSAS). Although in a number of studies an objective and subjective improvement in complaints such as morning fatigue, daytime sleepiness or concentration disorders was proven, up to $40 \%$ of the patients discontinued the CPAP treatment or only used it sporadically $[1,2]$. A recurrent reason for the discontinuation of therapy or for a low level of adherence are the nasal side effects of the treatment such as a runny nose, obstructed nasal breathing or drying out of the mucous membranes $[3,4]$. These side effects can be treated through supplementary use of a heated humidifier [5-8]. The conventional heated humidifiers consist of a hot plate, a water container

\section{KARGER}

E-Mail karger@karger.com

www.karger.com/res (c) 2016 S. Karger AG, Basel

0025-7931/16/0911-0018\$39.50/0
Wolfgang Galetke, $\mathrm{PhD}$

Krankenhaus der Augustinerinnen

Jakobstrasse 27-31

DE-50678 Cologne (Germany)

E-Mail wgaletke@koeln-kh-augustinerinnen.de 
and a control system which regulates the moisture released. Condensation can build up in the tube in the conventional humidifiers, particularly in cold temperatures, which reduces the humidification performance of the system and affects the patients.

Therefore, a humidification system was developed which contains a heated breathing tube as well as a water container and a hot plate. The algorithm of the system takes the room temperature, the applied CPAP and the flow into consideration and controls the performance of the hot plate and the heating coil in such a way that the individually set humidity level is maintained for the patients regardless of the factors stated. An initial study with this system at low room temperatures of roughly $14^{\circ} \mathrm{C}$ showed a low level of condensation build-up, few side effects and an improved patient sleep profile as compared to a conventional humidifier system. The study was, however, conducted in only one night [9]. In comparison to a CPAP system without humidification, the new system demonstrated a reduction of side effects, but neither an improvement in quality of life nor in treatment adherence, in a short-term study over 4 weeks [10].

The aim of the current study was, therefore, to test whether the use of a controlled heated breathing tube as compared to a conventional heated humidifier has an influence on satisfaction with the treatment and causes a reduction of side effects over a longer period and whether this leads to improved treatment adherence. A study period of 1 year was selected to account for the influence of the different seasons and variations in room temperature.

\section{Patients and Methods}

The study was conducted from March 2007 to August 2008 in an inpatient sleep laboratory connected to a university (Krankenhaus Bethanienl, Solingen, Germany). All patients with primarily diagnosed OSAS [apnea-hypopnea index (AHI) $>10 / \mathrm{h}$ in conjunction with clinical symptoms of a sleep apnea syndrome] requiring treatment were invited to participate in the study. Reasons for exclusion were: age $<18$ years, percentage of central respiratory events $>20 \%$ of the total AHI, exacerbated chronic obstructive pulmonary disease, cardiac insufficiency of New York Heart Association classes III and IV, uncontrolled arterial hypertension, serious cardiac arrhythmia, pregnancy and malignant diseases.

All participants gave their written consent to participate in the study. The study was approved by the Witten/Herdecke University Ethics Committee (approval No. 03/2007). The study was registered at the Australian New Zealand Clinical Trial Registry (ACTRN12607000203459). In this registry, 'treatment adherence' was reported falsely as the main outcome. This happened because of a misunderstanding in the trial registration process. As reported in this paper, the 'true' main outcome was satisfaction with the treatment according to the analogue scale.

Effect of a Heated Breathing Tube during CPAP Therapy

\section{Study Design}

The study is a randomized, controlled, operator-blinded, single-center study extending over 12 months. The study schedule is presented in figure 1 and was as follows: after enrolment in the study, the patients were randomly allocated to one of the two treatment groups. One group was supplied with a CPAP system with a heated humidifier and heated breathing tube (HC 602, ThermoSmart, Fisher and Paykel Healthcare, Auckland, New Zealand), the other group with a CPAP system and conventional heated humidifier, i.e. without heated breathing tube (HC 236, Fisher and Paykel Healthcare). Following meticulous mask adaptation and a practice phase of at least $4 \mathrm{~h}$ during the day, there was manual titration of the optimal CPAP in both treatment arms over 2 nights as part of an attended polysomnography (PSG). Subsequently, the patients were discharged from in-patient treatment with the determined fixed CPAP. During the study period, a crossover between the two groups was not allowed; therefore, none of the patients with a conventional heated humidifier additionally received a heated breathing tube.

\section{Polysomnography}

In-laboratory PSGs were performed using the Alice $4^{\circledR}$ Sleep Diagnostic System (Respironics, Murrysville, Pa., USA) and the SOMNOlab $^{\circledR}$ (Weinmann, Hamburg, Germany). The following parameters were recorded: electroencephalogram C4A1 and C3A2, submental electromyogram, electrooculogram, thoracic and abdominal efforts (piezoelectric plethysmography), respiratory flow (nasal pressure signal), snoring signal (laryngeal microphone), oxygen saturation (finger pulse oximetry) and pretibial electromyogram. Twelve sleep stages and arousals were analyzed in accordance with the guidelines of Rechtschaffen and Kales [11]. Arousals were defined as respiratory related when they occurred during or up to $2 \mathrm{~s}$ after an apnea or hypopnea, or in case of periodic breathing, when they occurred during hyperventilation. An apnea was defined as the cessation of respiratory flow for $\geq 10 \mathrm{~s}$. A hypopnea was defined as a reduction of nasal pressure signal (flow) of $\geq 50 \%$ for $\geq 10$ s accompanied by an arousal or a decrease in oxygen saturation of $\geq 3 \%$ [12]. Central apneas were scored if respiratory efforts were absent. The technician who analyzed the PSG was not involved in the study and, therefore, blinded to the treatment mode.

Quality of Life

Quality of life was assessed with the Calgary Sleep Apnea Quality of Life Index (SAQLI) for the baseline measurement and for the check-up after 12 months.

\section{Sleepiness}

Daytime sleepiness was measured using the Epworth Sleepiness Scale (ESS) for the baseline measurement and for the checkup after 12 months.

\section{Questionnaires}

Prior to treatment, all patients were asked about any existing problems or complaints regarding the nose and throat, about previous operations in this area and about medication (questionnaire 1). After 1, 6 and 12 months, the patients answered a questionnaire on side effects during treatment (questionnaire 2). The level of satisfaction with the treatment was determined after 1, 6 and 12 months by using an analogue scale consisting of 7 items (questionnaire 3). 


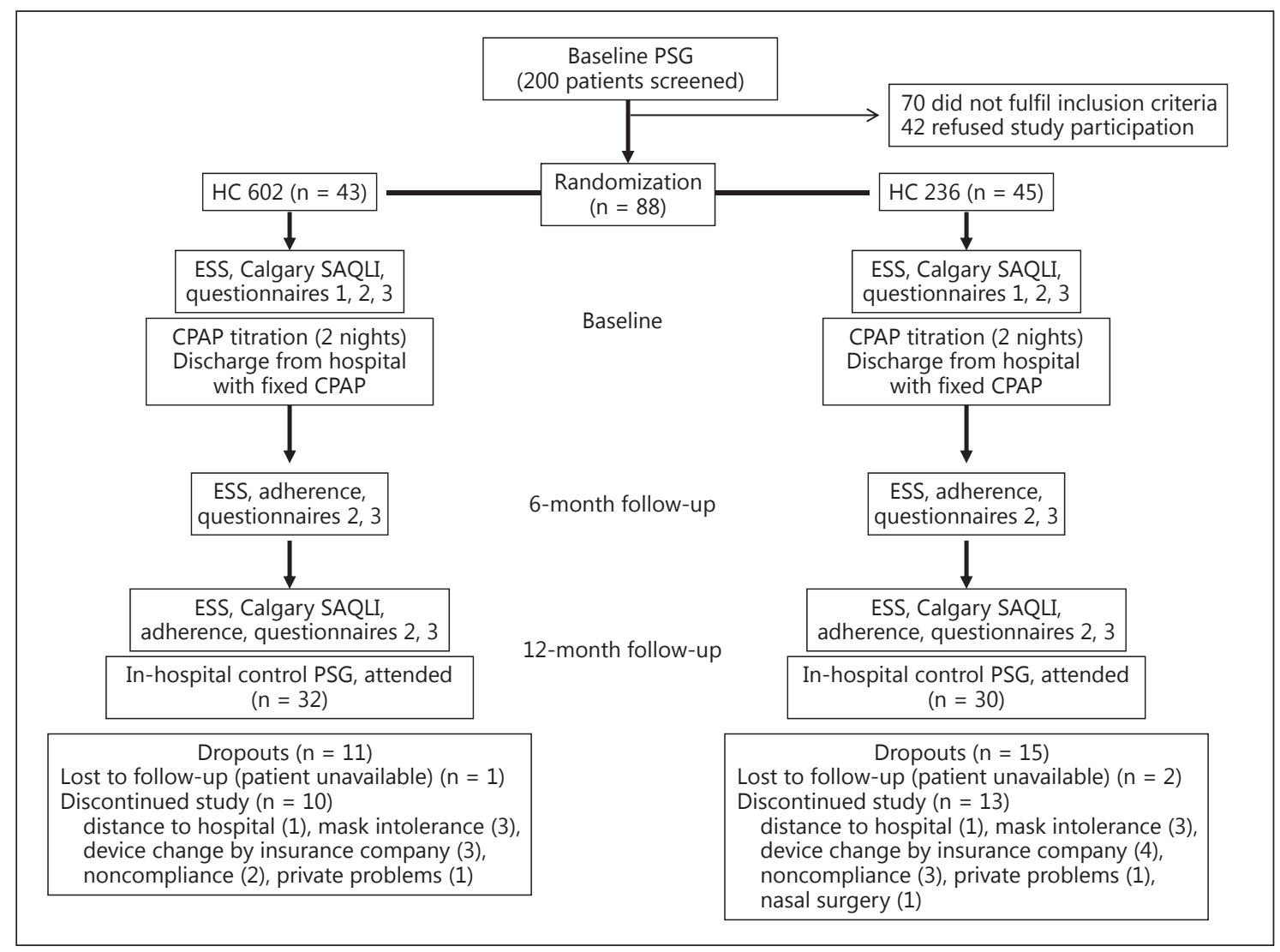

Fig. 1. Flow chart of the study protocol.

\section{Adherence}

Adherence to treatment was recorded from the reading on the run-time counter, which is inherent in the system, after 6 and 12 months. Only the machine time at effective pressure was considered.

\section{Room Temperature}

The patients were asked about the typical temperature in the bedroom after 6 and 12 months. There were 6 predefined temperature categories: category 1 : temperature under $14^{\circ} \mathrm{C}$; category 2 : 14 to $<17^{\circ} \mathrm{C}$; category $3: 17$ to $<20^{\circ} \mathrm{C}$; category $4: 20$ to $<23^{\circ} \mathrm{C}$; category 5: 23 to $<26^{\circ} \mathrm{C}$ and category $6: \geq 26^{\circ} \mathrm{C}$.

\section{Statistics}

The primary endpoint of the study was the level of satisfaction with the treatment after 12 months, measured with the analogue scale (questionnaire 3). The secondary endpoints were treatment adherence, quality of life and stated side effects (questionnaire 2). The basis for the sample size calculations was the study by Massie et al. [5], in which the level of satisfaction with the treatment was also determined using the analogue scale. Based on this study, a total number of 70 patients was required to prove a difference between the two treatment modes in the case of a type 1 error of $5 \%$ and a power of $80 \%$.
All analyses were conducted on the per protocol data set. Numeric variables such as anthropometric and PSG data are expressed as means \pm standard deviations. Between-group comparisons were performed using an adjusted linear regression with the 12 -month value as the dependent variable and the baseline value and treatment group as the independent variables. Differences in each parameter between the two treatment groups were analyzed using an independent samples t test. In case of nonnormality, the Mann-Whitney U test was used. Data analysis was performed in SPSS for Windows, version 11.5 (SPSS Inc., Chicago, Ill., USA).

\section{Results}

Eighty-eight patients (69 men; mean age $54.4 \pm 11.9$ years; average body mass index $32.5 \pm 6.7$ ) were included in the study. In the treatment arm with the conventional humidifier (HC 236), 15 of the initial 45 patients (33.3\%) terminated the study early, while in the treatment arm with the heated breathing tube (HC 602), 11 of the 43 patients (25.6\%) terminated the study early (fig. 1). Therefore, data on 62 patients were available for the final analysis. 
Table 1. Subjective sleepiness, anthropometric and polysomnographic parameters of the complete study group

\begin{tabular}{|c|c|c|c|c|}
\hline & \multicolumn{2}{|l|}{ Baseline } & \multicolumn{2}{|l|}{12 months } \\
\hline & $\begin{array}{l}\text { conventional } \\
\text { humidifier }\end{array}$ & $\begin{array}{l}\text { controlled heated } \\
\text { breathing tube } \\
\text { humidifier }\end{array}$ & $\begin{array}{l}\text { conventional } \\
\text { humidifier }\end{array}$ & $\begin{array}{l}\text { controlled heated } \\
\text { breathing tube } \\
\text { humidifier }\end{array}$ \\
\hline Age, years & $54.4 \pm 11.9$ & $54.0 \pm 11.3$ & & \\
\hline Sex (male/female), n & $34 / 11$ & $35 / 8$ & & \\
\hline BMI & $32.4 \pm 6.3$ & $32.7 \pm 7.2$ & & \\
\hline AHI total, /h & $39.5 \pm 21.5$ & $40.3 \pm 24.9$ & $11.5 \pm 10.2^{\mathrm{a}}$ & $6.0 \pm 5.8^{\mathrm{a}}$ \\
\hline Arousal resp., /h & $20.3 \pm 15.7$ & $20.3 \pm 20.0$ & $11.3 \pm 7.8^{\mathrm{a}}$ & $13.9 \pm 11.4^{\mathrm{a}}$ \\
\hline $\mathrm{SaO}_{2} \min ., \%$ & $74.1 \pm 13.6$ & $80.2 \pm 10.3$ & $86.0 \pm 3.8^{\mathrm{a}}$ & $87.3 \pm 4.2^{\mathrm{a}}$ \\
\hline Time $<90 \% \mathrm{SaO}_{2}$, min & $16.4 \pm 19.8$ & $13.7 \pm 21.2$ & $1.2 \pm 3.6^{\mathrm{a}}$ & $1.0 \pm 3.2^{\mathrm{a}}$ \\
\hline TST, $\min$ & $365.4 \pm 51.1$ & $352.7 \pm 75.6$ & $334.1 \pm 48.3^{\mathrm{b}}$ & $333.4 \pm 58.0^{c}$ \\
\hline WASO, min & $54.5 \pm 49.2$ & $51.8 \pm 42.6$ & $36.3 \pm 35.5$ & $38.5 \pm 37.7$ \\
\hline REM, \%TST & $14.5 \pm 7.7$ & $14.5 \pm 7.2$ & $16.4 \pm 6.9$ & $21.4 \pm 8.6^{\mathrm{b}}$ \\
\hline S1/S2, \%TST & $69.4 \pm 13.8$ & $67.6 \pm 15.5$ & $52.5 \pm 17.6^{\mathrm{a}}$ & $54.0 \pm 17.8^{\mathrm{a}}$ \\
\hline S3/S4, \%TST & $16.1 \pm 11.5$ & $17.9 \pm 12.9$ & $31.0 \pm 17.0^{\mathrm{a}}$ & $24.5 \pm 17.9^{\mathrm{b}}$ \\
\hline ESS score & $9.1 \pm 4.7$ & $8.3 \pm 3.7$ & $6.1 \pm 3.9^{b}$ & $6.6 \pm 5.8^{\mathrm{a}}$ \\
\hline
\end{tabular}

Values are means \pm SD unless otherwise indicated. BMI = Body mass index; AHI total = total number of apneas and hypopneas per hour of total sleep time; Arousal resp. = number of respiration-associated EEG arousals per hour of total sleep time; $\mathrm{SaO}_{2}$ min. = minimal oxygen saturation; Time $<90 \% \mathrm{SaO}_{2}=$ time with oxygen saturation below $90 \%$; TST = total sleep time; WASO = wake after sleep onset; REM = rapid eye movement; REM, $\% \mathrm{TST}$ = proportion of REM stage of total sleep time; S1/S2, \%TST = proportion of sleep stages 1 and 2 of total sleep time; S3/S4, \%TST $=$ proportion of sleep stages 3 and 4 of total sleep time. ${ }^{\mathrm{a}} \mathrm{p}<0.001,{ }^{\mathrm{b}} \mathrm{p}<0.01,{ }^{\mathrm{c}} \mathrm{p}<0.05$ versus baseline.

Table 2. Preferred room temperature (according to patients' statement) and set value of hot plate

\begin{tabular}{cccc}
\hline & Total group & $\begin{array}{l}\text { Conventional } \\
\text { humidifier }\end{array}$ & $\begin{array}{l}\text { Controlled } \\
\text { heated } \\
\text { breathing tube } \\
\text { humidifier }\end{array}$ \\
\hline & & & $2.8 \pm 1.3$ \\
\hline $\begin{array}{l}\text { Hot plate set value } \\
\text { Room temperature }\end{array}$ & $2.9 \pm 1.6$ & $2.9 \pm 1.9$ & \\
$<14^{\circ} \mathrm{C}$ & $5(8.3)$ & $3(10.3)$ & $2(6.5)$ \\
$14-<17^{\circ} \mathrm{C}$ & $17(28.3)$ & $11(37.9)$ & $6(19.6)$ \\
$17-<20^{\circ} \mathrm{C}$ & $27(45.0)$ & $12(41.4)$ & $15(48.4)$ \\
$20-<23^{\circ} \mathrm{C}$ & $9(15.0)$ & $3(10.3)$ & $6(19.4)$ \\
$23-<26^{\circ} \mathrm{C}$ & $2(3.3)$ & 0 & $2(6.5)$ \\
$\geq 26^{\circ} \mathrm{C}$ & $2(3.3)$ & $1(3.3)$ & $1(3.3)$ \\
\hline
\end{tabular}

Values are $\mathrm{n}(\%)$

At baseline, the AHI was $39.9 \pm 23.1 / \mathrm{h}$ in the total study population, and the ESS overall score was $8.7 \pm 4.2$. With the exception of minimal oxygen saturation, there were no significant differences between the two groups with regard to the anthropometric and polysomnographic parameters at the baseline measurement (table 1).

Both treatment groups displayed an equally good, significant improvement in respiratory events, in total and respiratory arousals, in average and minimal oxygen saturation and in the ESS overall scores. There was no difference between the treatment arms with regard to the sleep stages and other sleep parameters (table 1).

Most patients in both treatment arms preferred a room temperature between 17 and $20^{\circ} \mathrm{C}$. The set humidification intensity did not differ between the two treatment groups (table 2).

There was no significant difference between the two treatment groups after 6 or 12 months in any of the items of the visual analogue scale except subscale 6 after 12 months (fig. 2; table 3). After 12 months, the mean difference in overall satisfaction between the two treatment groups (subscale 3) was -14.1 , which demonstrated a strong trend in favor of the treatment with the heated breathing tube but without statistical significance ( $\mathrm{p}=$ 0.059 ). There was also no significant difference in the side effects for all items after 12 months of treatment. After 1 and 6 months, the patients with the heated breathing tube 

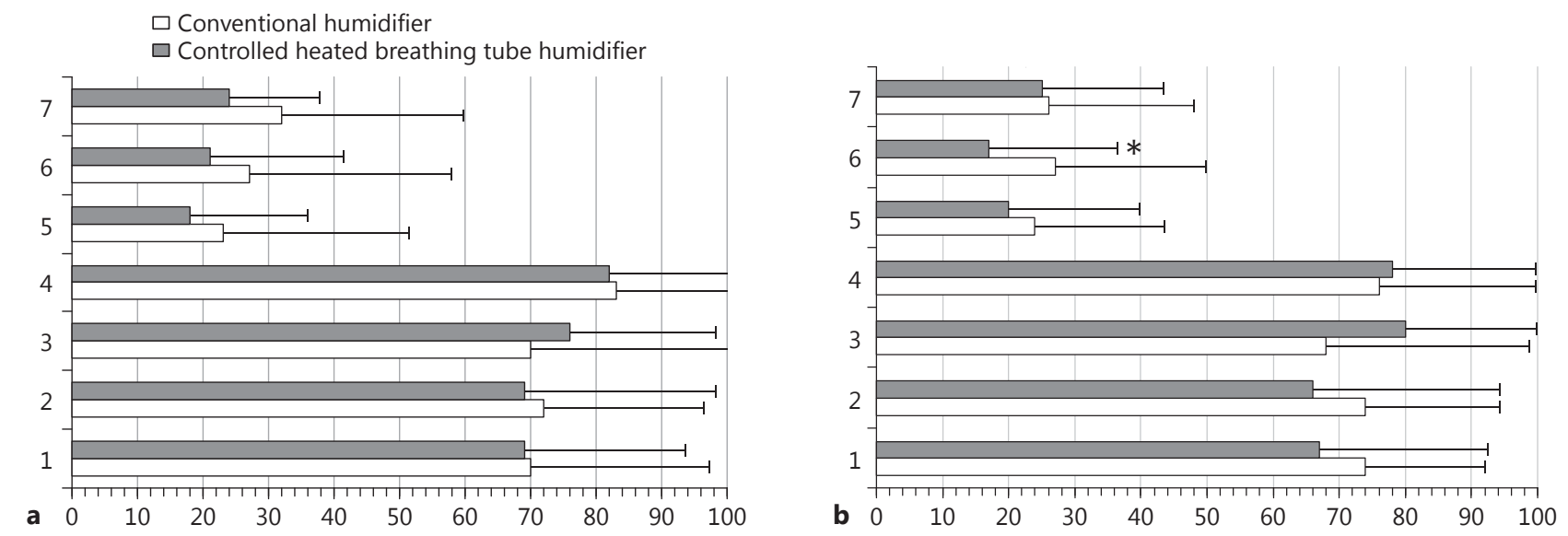

Fig. 2. Level of satisfaction with the treatment after 6 months (a) and after 12 months (b) using an analogue scale (mean values \pm $\mathrm{SD}) .{ }^{*} \mathrm{p}<0.05$. 1 : How did you sleep last night? $(0=$ very, very bad; $100=$ very good $) .2$ : How rested do you feel today? $(0=$ not rested at all; $100=$ very rested). 3 : How satisfied are you with the CPAP treatment? $(0=$ not satisfied; $100=$ very satisfied $)$. 4 : Did you ex-

perience any complaints regarding the nose or the throat last night? $(0=$ many complaints; $100=$ no complaints $) .5$ : Inspiration during CPAP treatment is $\ldots(0=$ very easy; $100=$ very hard $) .6$ : Expiration during CPAP treatment is ... ( 0 = very easy; $100=$ very hard). 7: How do you experience the CPAP? $(0=$ very easy; $100=$ very hard).

Table 3. Mean values and mean differences in visual analogue scale scores between the conventional humidifier (HC 236) and the controlled heated breathing tube humidifier (HC 602) groups

\begin{tabular}{|c|c|c|c|c|}
\hline Item & HC 236 & HC 602 & $\begin{array}{l}\text { Mean difference } \\
(95 \% \mathrm{CI})^{1}\end{array}$ & $\mathrm{p}$ value \\
\hline How did you sleep last night? $(0=$ very, very bad; $100=$ very good $)$ & $73.9 \pm 19.7$ & $66.7 \pm 26.1$ & $6.2(-5.7$ to 18.1$)$ & 0.301 \\
\hline How rested do you feel today? $(0=$ not rested at all; $100=$ very rested $)$ & $74.0 \pm 20.8$ & $66.0 \pm 28.5$ & $7.2(-5.7$ to 20.1$)$ & 0.265 \\
\hline $\begin{array}{l}\text { How satisfied are you with the CPAP treatment? }(0=\text { not satisfied; } 100=\text { very satisfied }) \\
\text { Did you experience any complaints regarding the nose or the throat last night? }\end{array}$ & $68.3 \pm 31.7$ & $79.9 \pm 22.8$ & $-14.1(-28.7$ to 0.6$)$ & 0.059 \\
\hline$(0=$ many complaints; $100=$ no complaints $)$ & $76.2 \pm 30.1$ & $78.4 \pm 29.5$ & $-3.7(-19.6$ to 12.3$)$ & 0.647 \\
\hline Inspiration during CPAP treatment is $\ldots(0=$ very easy; $100=$ very hard $)$ & $23.9 \pm 19.1$ & $19.5 \pm 20.3$ & $5.4(-4.8$ to 15.5$)$ & 0.292 \\
\hline Expiration during CPAP treatment is $\ldots(0=$ very easy; $100=$ very hard $)$ & $26.8 \pm 23.3$ & $17.1 \pm 19.5$ & $12.7(0.7$ to 24.6$)$ & $<0.05$ \\
\hline How do you experience the CPAP? $(0=$ very easy; $100=$ very hard $)$ & $26.4 \pm 21.5$ & $24.9 \pm 18.5$ & $5.1(-6.4$ to 16.5$)$ & 0.380 \\
\hline
\end{tabular}

Values are means \pm SD unless otherwise indicated. ${ }^{1}$ Mean difference HC 236 - HC 602.

complained about significantly less condensation in the tube than the patients in the other group, but after 12 months, the difference was considerably less pronounced. We rarely noticed dry mucous membranes in either treatment group; there was no difference between the systems concerning this item (table 4 ).

The quality of life improved in the domains 'daily activities', 'social behavior' and 'emotions' for both treatment arms as opposed to the initial value; this was only significant in the HC 602 arm for the domain 'emotions'. There was no significant difference between the two treatment groups (table 5).

The adherence to treatment in the group with the heated breathing tube $(4.96 \pm 1.95 \mathrm{~h} /$ night $)$ was on average almost $1 \mathrm{~h}$ longer than in the other group $(3.9 \pm 2.54 \mathrm{~h} /$ night) after 12 months, but the difference was not significant $(p=0.0602)$. Both groups displayed an increase in adherence during the study (table 6). 
Table 4. Side effects in both treatment modes at 1, 6 and 12 months

\begin{tabular}{|c|c|c|c|c|c|c|}
\hline & \multicolumn{2}{|l|}{1 month } & \multicolumn{2}{|l|}{6 months } & \multicolumn{2}{|l|}{12 months } \\
\hline & $\begin{array}{l}\text { conventional } \\
\text { humidifier }\end{array}$ & $\begin{array}{l}\text { controlled heated } \\
\text { breathing tube } \\
\text { humidifier }\end{array}$ & $\begin{array}{l}\text { conventional } \\
\text { humidifier }\end{array}$ & $\begin{array}{l}\text { controlled heated } \\
\text { breathing tube } \\
\text { humidifier }\end{array}$ & $\begin{array}{l}\text { conventional } \\
\text { humidifier }\end{array}$ & $\begin{array}{l}\text { controlled heated } \\
\text { breathing tube } \\
\text { humidifier }\end{array}$ \\
\hline \multicolumn{7}{|l|}{ Pressure marks by mask or } \\
\hline straps & $0.9 \pm 0.7$ & $1.3 \pm 0.9$ & $1.1 \pm 0.9$ & $1.1 \pm 1.0$ & $1.1 \pm 0.9$ & $1.1 \pm 1.0$ \\
\hline Ambient noise by the device & $1.0 \pm 1.0$ & $0.9 \pm 0.7$ & $1.0 \pm 0.9$ & $0.6 \pm 0.7$ & $0.9 \pm 1.0$ & $0.7 \pm 0.9$ \\
\hline Cold nose or face & $0.5 \pm 0.9$ & $0.2 \pm 0.4$ & $0.4 \pm 0.6$ & $0.3 \pm 0.7$ & $0.5 \pm 0.7$ & $0.4 \pm 0.9$ \\
\hline Claustrophobia & $0.2 \pm 0.5$ & $0.5 \pm 1.0$ & $0.2 \pm 0.6$ & $0.3 \pm 0.6$ & $0.3 \pm 0.8$ & $0.2 \pm 0.6$ \\
\hline Dry mouth & $0.8 \pm 0.8$ & $0.8 \pm 1.1$ & $1.1 \pm 1.0$ & $0.9 \pm 0.9$ & $0.8 \pm 0.8$ & $0.8 \pm 0.8$ \\
\hline Rhinitis & $0.4 \pm 0.6$ & $0.3 \pm 0.4$ & $0.3 \pm 0.5$ & $0.2 \pm 0.5$ & $0.2 \pm 0.5$ & $0.3 \pm 0.7$ \\
\hline \multicolumn{7}{|l|}{ Problems breathing through } \\
\hline Dyspnea & $0.2 \pm 0.5$ & $0.3 \pm 0.7$ & $0.1 \pm 0.6$ & $0.3 \pm 0.6$ & $0.5 \pm 1.0$ & $0.5 \pm 0.9$ \\
\hline Chest pain & $0.1 \pm 0.4$ & $0.2 \pm 0.4$ & $0.1 \pm 0.4$ & $0.3 \pm 0.7$ & $0.1 \pm 0.3$ & $0.2 \pm 0.5$ \\
\hline Skin irritation & $0.1 \pm 0.3$ & $0.2 \pm 0.4$ & $0.2 \pm 0.6$ & $0.1 \pm 0.3$ & $0.4 \pm 0.8$ & $0.3 \pm 0.5$ \\
\hline Pressure intolerance & $0.2 \pm 0.4$ & $0.2 \pm 0.6$ & $0.2 \pm 0.6$ & $0.2 \pm 0.5$ & $0.3 \pm 0.8$ & $0.2 \pm 0.4$ \\
\hline Mask or tube condensation & $1.6 \pm 1.1$ & $1.0 \pm 0.7^{\mathrm{a}}$ & $1.7 \pm 1.0$ & $0.8 \pm 1.0^{\mathrm{b}}$ & $1.3 \pm 1.0$ & $1.0 \pm 0.8$ \\
\hline
\end{tabular}

Values are means \pm SD. $0=$ Never appearing; $1=$ rarely appearing, therapy was not influenced; $2=$ occasionally appearing, therapy was sometimes discontinued; 3 = frequently appearing, therapy was frequently discontinued. ${ }^{\mathrm{a}} \mathrm{p}<0.001$ versus conventional humidifier at 1 month; ${ }^{\mathrm{b}} \mathrm{p}<0.001$ versus conventional humidifier at 6 months.

Table 5. Quality of life (Calgary SAQLI) scores with both treatment modes

\begin{tabular}{llllll}
\hline SAQLI & \multicolumn{2}{l}{ Conventional humidifier } & & \multicolumn{2}{l}{$\begin{array}{l}\text { Controlled heated breathing } \\
\text { tube humidifier }\end{array}$} \\
& baseline & 12 months & & baseline & 12 months \\
\hline A (Daily functioning) & $4.7 \pm 1.5$ & $4.9 \pm 1.7$ & & $4.9 \pm 1.2$ & $5.5 \pm 1.2$ \\
B (Social interactions) & $5.1 \pm 1.5$ & $5.2 \pm 1.6$ & & $5.0 \pm 1.3$ & $5.4 \pm 1.0$ \\
C (Emotional functioning) & $4.6 \pm 1.5$ & $5.0 \pm 1.6$ & & $4.7 \pm 1.0$ & $5.2 \pm 1.3^{\mathrm{a}}$ \\
D (Symptoms) & $0.7 \pm 0.4$ & $0.7 \pm 0.4$ & & $0.7 \pm 0.4$ & $0.7 \pm 0.5$ \\
E (Treatment-related symptoms) & & $0.5 \pm 0.4$ & & & $0.5 \pm 0.4$ \\
\hline
\end{tabular}

Values are means $\pm \mathrm{SD} .{ }^{\mathrm{a}} \mathrm{p}<0.01$ versus baseline.

Table 6. Adherence with both treatment modes

\begin{tabular}{llllll}
\hline & \multicolumn{2}{l}{ Conventional humidifier } & & \multicolumn{2}{l}{$\begin{array}{l}\text { Controlled heated breathing tube } \\
\text { humidifier }\end{array}$} \\
\cline { 2 - 3 } \cline { 5 - 6 } & 6 months & 12 months & & 6 months & 12 months \\
\hline Adherence, h/night & $3.89 \pm 2.59$ & $3.90 \pm 2.54$ & & $4.93 \pm 2.28$ & $4.96 \pm 1.95$ \\
\hline
\end{tabular}

Values are means \pm SD. 


\section{Discussion}

The results of this study on unselected patients with OSAS show that the additional use of a controlled heated breathing tube in heated humidification during CPAP treatment as compared to conventional heated humidification with similarly good treatment effectiveness has no effect on the patients' level of satisfaction and the emergence of side effects and does not increase the adherence to treatment significantly.

The adherence to CPAP treatment for OSAS depends greatly on the side effects experienced by the patients [12]. Problems in the upper airways such as dry nasal or pharyngeal mucous membranes, a blocked nose or rhinitis are common when using pressure treatment $[3,4]$. These complaints often lead to the additional prescription of humidifier systems. Heated humidification systems are the standard as, in contrast to heat and moisture exchangers and cold-air humidifiers, these provide effective humidification of the mucous membranes [13-15]. Conventional heated humidifiers can - in particular at a cold room temperature - promote the build-up of condensation in the tube system, which may create an adverse effect on the patient [16]. To avoid this problem, a heated humidifier with a heated breathing tube was developed. A pilot study demonstrated that, at least at cooler room temperatures, the build-up of condensation was reduced and the emergence of side effects in the patients could be lessened [9]. However, in another study, this system did not improve adherence after 4 weeks of treatment [10]. It is unclear whether a longer therapy period has an effect on the adherence to treatment and the level of patient satisfaction.

As far as the authors know, this is the first study that investigates the influence of a heated breathing tube on the effectiveness, adherence and side effect rate during CPAP treatment over an extended period. The period of 1 year was consciously chosen as an observation period to eliminate the influence of the seasons on the study results. The results of the study showed an equivalence of both systems with regard to the reduction of respiratory events and the improvement in daytime sleepiness. There was also no difference between the two treatment modifications in the primary endpoint, i.e. the level of satisfaction with the therapy, although a strong trend in favor of the heated breathing tube was documented. It is, however, remarkable that the most common side effect mentioned by the group with the conventional heated humidifier was the build-up of condensation in the tube or in the mask, while the other group with the heated breathing tube seldom complained of this side effect. This subjective impression corresponds to the objective study data from Nilius et al. [9], although the patients in our study preferred a warmer room temperature. However, although significantly different after 1 and 6 months, after 12 months of treatment this side effect was less frequently stated by the patients with the conventional humidifier, and the difference between the two treatment groups was no longer significant. It can be speculated that after 12 months the patients with a conventional humidifier became accustomed to the condensation in the interface, although this was not verified in the study. Nevertheless, the patients with the heated breathing tube used their treatment on average $1 \mathrm{~h}$ longer per night, which indicates a notable improvement in adherence and could hardly be attained in previous studies by treatment modification [17-19]. The difference did not reach statistical significance, but it was close to significance. The reason for the missing statistical significance is probably the fact that the study was powered by the difference in the level of satisfaction with the treatment and not the difference in adherence.

Several further features of the study remain to be discussed. To evaluate the effect of the heated breathing tube, we compared it with an existing, very effective device, i.e. a conventional heated humidifier, and not with a cold-air humidifier or a CPAP system without humidifier. Previous studies demonstrated the heated humidifier's superiority to a cold-air humidifier or no humidification at all $[5,13]$, so that we can speculate whether the differences in the primary and secondary endpoints would after all become significant if compared to another device. On the other hand, in previous studies, a heated humidifier compared to no humidification did not invariably lead to an improvement in adherence and quality of life [8]. However, the heated humidifier has since then become the standard procedure for humidification in positive pressure treatment, so that in our opinion every other technical modification has to measure up to this standard. Furthermore, we should emphasize that this study was not conducted on selected patients with existing nasal complaints, and the results, therefore, refer only to unselected patients. An older study showed that CPAP patients with previous nasal operations, chronic rhinitis or permanent medical treatment of the upper airways in particular benefit from humidification [7]. There should be a discussion on whether further studies on heated humidification should focus on these patients. Another limitation of the study is that we did not measure the room temperature but asked the patients about it. Permanent measurements of room temperatures over a 1-year period would without a doubt have been too complex. The uniform distribution 
of the stated room temperatures in both treatment arms also indicates that similar conditions prevailed in both groups. Surprisingly, the improvement in quality of life with both treatment modes was modest and did not reach statistical significance for most outcomes. This might be due to the fact that the study was underpowered to detect an effect of CPAP on quality of life. In addition, the relatively high residual AHI in the conventional humidifier group after 12 months has to be discussed. Despite careful mask fitting, 2 patients in this group had an AHI of 29.9 and $43.4 / \mathrm{h}$, respectively, at the follow-up after 12 months, which was due to a substantial mask leakage. However, because this problem occurred only during the follow-up night, we believe that it did not have a relevant influence on the results of the study. Finally, the relatively high dropout rate of 26 and $33 \%$, respectively, in the two study arms should be discussed. All study patients underwent the standard procedure in our sleep laboratory, which included meticulous mask adaptation, a discussion of the illness, a written and oral explanation of the devices and several hours of practice phases during the day. With regard to high dropout rates, it must be taken into consideration that the 1-year study period was rather long. In previous studies, similar adherence rates were stated when the observation period was that long. In a study from our sleep laboratory, the dropout rate was $27 \%$ after 1 year [12], meaning that the number of study dropouts in the current study is within the known scope.

In conclusion, we can infer from this study that a general use of a heated humidifier with heated breathing tube during positive pressure therapy cannot be recommended for patients with OSAS. Possibly, in future studies, subgroups of patients can be identified who would benefit from this treatment modification.

\section{Financial Disclosure and Conflicts of Interest}

Fisher and Paykel Healthcare gave financial support to the study but was involved neither in designing or conducting the study nor in preparing the manuscript.

\section{References}

-1 McArdle N, Devereux G, Heidarnejad H, Engleman HM, Mackay TW, Douglas NJ: Longterm use of CPAP therapy for sleep apnea/ hypopnea syndrome. Am J Respir Crit Care Med 1999;159:1108-1114.

-2 Sawyer AM, Gooneratne NS, Marcus CL, Ofer D, Richards KC, Weaver TE: A systematic review of CPAP adherence across age groups: clinical and empiric insights for developing CPAP adherence interventions. Sleep Med Rev 2011;15:343-356.

-3 Pepin JL, Leger P, Veale D, Langevin B, Robert D, Levy P: Side effects of nasal continuous positive airway pressure in sleep apnea syndrome. Study of 193 patients in two French sleep centers. Chest 1995; 107:375-381.

-4 Kreivi HR, Virkkula P, Lehto J, Brander P: Frequency of upper airway symptoms before and during continuous positive airway pressure treatment in patients with obstructive sleep apnea syndrome. Respiration 2010;80:488-494.

5 Massie CA, Hart RW, Peralez K, Richards GN: Effects of humidification on nasal symptoms and compliance in sleep apnea patients using continuous positive airway pressure. Chest 1999;116:403-408.

-6 Neill AM, Wai HS, Bannan SP, Beasley CR, Weatherall M, Campbell AJ: Humidified nasal continuous positive airway pressure in obstructive sleep apnoea. Eur Respir J 2003;22: 258-262.

7 Rakotonanahary D, Pelletier-Fleury N, Gagnadoux F, Fleury B: Predictive factors for the need for additional humidification during nasal continuous positive airway pressure therapy. Chest 2001;119:460-465.

-8 Mador MJ, Krauza M, Pervez A, Pierce D, Braun M: Effect of heated humidification on compliance and quality of life in patients with sleep apnea using nasal continuous positive airway pressure. Chest 2005;128:2151-2158.

-9 Nilius G, Domanski U, Franke KJ, Rühle KH: Impact of a controlled heated breathing tube humidifier on sleep quality during CPAP therapy in a cool sleeping environment. Eur Respir J 2008;31:830-836.

10 Rühle KH, Franke KJ, Domanski U, Nilius G: Quality of life, compliance, sleep and nasopharyngeal side effects during CPAP therapy with and without controlled heated humidification. Sleep Breath 2011;15:479-485.

11 Rechtschaffen A, Kales A: A Manual of Standardized Terminology Techniques and Scoring System for Sleep Stages of Human Subjects. Brain Information Service. Los Angeles, University of California, 1968.

12 Iber C, Ancoli-Israel S, Chesson A, Quan SF; American Academy of Sleep Medicine: The AASM Manual for the Scoring of Sleep and Associated Events: Rules, Terminology and Technical Specifications, ed 1. Westchester, American Academy of Sleep Medicine, 2007.

13 Galetke W, Puzzo L, Priegnitz C, Anduleit N, Randerath WJ: Long-term therapy with continuous positive airway pressure in obstructive sleep apnea: adherence, side effects and predictors of withdrawal - a 'real life' study. Respiration 2011;82:155-161.
14 Randerath WJ, Meier J, Genger H, Domanski $\mathrm{U}$, Rühle KH: Efficiency of cold passover and heated humidification under continuous positive airway pressure. Eur Respir J 2002;20: 183-186.

15 Wiest GH, Harsch IA, Fuchs FS, Kitzbichler S, Bogner K, Brueckl WM, Hahn EG, Ficker $\mathrm{JH}$ : Initiation of CPAP therapy for OSA: does prophylactic humidification during CPAP pressure titration improve initial patient acceptance and comfort? Respiration 2002;69: 406-412.

16 Duong M, Jayaram L, Camfferman D, Catcheside P, Mykytyn I, McEvoy RD: Use of heated humidification during nasal CPAP titration in obstructive sleep apnoea syndrome. Eur Respir J 2005;26:679-685.

17 Bacon JP, Farney RJ, Jensen RL, Walker JM, Cloward TV: Nasal continuous positive airway pressure devices do not maintain the set pressure dynamically when tested under simulated clinical conditions. Chest 2000;118: 1441-1449.

18 Haniffa M, Lasserson TJ, Smith I: Interventions to improve compliance with continuous positive airway pressure for obstructive sleep apnoea. Cochrane Database Syst Rev 2004; CD003531.

19 Smith I, Lasserson TJ: Pressure modification for improving usage of continuous positive airway pressure machines in adults with obstructive sleep apnoea. Cochrane Database Syst Rev 2009;CD003531. 